\title{
The fatigue performance of titanium alloys joined via the powder interlayer bonding method
}

\author{
P. Davies ${ }^{1} \cdot$ A. Johal ${ }^{1} \cdot$ H. Davies ${ }^{1} \cdot$ S. Marchisio ${ }^{2}$
}

Received: 24 March 2020 / Accepted: 6 July 2020 / Published online: 17 July 2020

(C) The Author(s) 2020

\begin{abstract}
This study investigated the fatigue performance of two forged variations of $\alpha+\beta$ titanium alloys, namely Ti-6Al-4V (Ti-6-4) and Ti-6Al-2Sn-4Zr-6Mo (Ti-6-2-4-6) joined via the powder interlayer bonding (PIB) process. Both alloys were bonded at relevant temperatures in the specific alloy's $\alpha+\beta$ region. Modifications to the microstructure during the bonding process where it recrystalised into a bi-modal structure, resulted in improved low cycle fatigue (LCF) response for the Ti-6-4 alloy. This improvement is seen throughout the fatigue curve when compared to the LCF performance of the as received Ti-6- 4 material. The improvement in LCF performance resulting from the microstructure transformation overcomes any reduction in performance that can be attributed to retained porosity after the bonding cycle. While the HCF performance of the Ti-6-2-4-6 alloy joined via the PIB process fell below that of the as received $\beta$-forged billet material, the fatigue performance compares well with previous HCF results for welded material. Unlike the Ti-6-4 alloy, the $\beta$-forged Ti-6-2-4-6 alloy does not benefit from the transformation of its microstructure throughout the bond region.
\end{abstract}

Keywords Powder interlayer bonding (PIB) $\cdot$ Ti-6-4 · Ti-6-2-4-6 · Fatigue

\section{Introduction}

The $\alpha+\beta$ titanium alloys Ti-6Al-4V (Ti-6-4) and Ti-6Al2Sn-4Zr-6Mo (Ti-6-2-4-6) are both extensively used for gas turbine applications, due to their excellent balance of mechanical properties such as high strength and excellent fatigue response. Since their introduction titanium alloy usage has continued to grow along with the evolution of the gas turbine; with the alloys accounting for over $25 \%$ of the weight of a modern engine [1]. Titanium alloys are typically found in the front end of gas turbines. Ti-6-4 is often utilised for both rotating and structural applications such as fans and casings [2], below $350^{\circ} \mathrm{C}$. With improved creep resistance over Ti-64 , good fatigue properties and toughness at elevated temperatures, Ti-6-2-4-6 is often used when the temperature requirement increases and it is widely employed for compressor discs

P. Davies

p.d.davies@swansea.ac.uk

1 Institute of Structural Materials, College of Engineering, Swansea University, Bay Campus, Fabian Way, Swansea SA1 8EN, UK

2 Rolls-Royce Plc, Box 31, Derby, PO DE24 8BJ, UK
$[3,4]$. Titanium undergoes an allotropic phase transformation at $882{ }^{\circ} \mathrm{C}$ from a hcp $\alpha$ phase to a bcc $\beta$ phase. Alloying elements can have a stabilising effect on the $\alpha$ phase by raising the $\alpha / \beta$ transition temperature, or stabilise the $\beta$ phase by lowering the transition temperature [5]. It has been reported that Ti-6-4 [6] and Ti-6-2-4-6 [7] have a $\beta_{\mathrm{T}}$ of $996{ }^{\circ} \mathrm{C} \pm 14{ }^{\circ} \mathrm{C}$ and $935^{\circ} \mathrm{C}$ respectively. Manipulation of the transition temperature allows for variations in the percentage of each phase at room temperature. Together with the processing route, this enables the development of a range of microstructures [8], providing the alloys with their inherent mechanical properties. It is possible to produce three distinctly different microstructures in the two phase $\alpha+\beta$ alloys such as Ti-6-4 and Ti-6-2$4-6$ by varying the thermomechanical processes: an equiaxed microstructure, a fully lamellar microstructure, and a bi-model structure consisting of equiaxed primary $\alpha\left(\alpha_{p}\right)$ in an $\alpha+\beta$ matrix, which in turn can have a significant effect on their fatigue properties [9]. Combined with $\alpha$ grain size, ageing condition and texture the morphology of the $\alpha$ and $\beta$ phases strongly affects the fatigue properties of titanium alloys. Other microstructural parameters which can affect the fatigue performance of these alloys include prior $\beta$ grain size, lamellar colony size and the width of the individual $\alpha$ lamellae in lamellar microstructures [10]. 
The crack initiation life for titanium alloys can be a very small fraction of the overall fatigue life at high stress and strain amplitudes. As a result, a components lifetime under low cycle fatigue (LCF) conditions is dominated by its ability to resist fatigue crack propagation. The part attributable to crack initiation increases continuously with decreasing stress amplitudes. Therefore, the high cycle fatigue strength (HCF) of titanium alloys can be considered a reliable measure of resistance to fatigue crack initiation [11].

Fusion welding techniques such as tungsten inert gas (TIG) welding and laser beam (LB) welding can be used successfully to produce high-quality joints in titanium alloys. Fusion welding processes melt and re-solidify the materials at the joint interface or fusion zone (FZ), while also creating a heat-affected zone (HAZ) of varying sizes. On cooling, transformed microstructures develop [12] in these zones which can have a negative effect on their mechanical properties [13]. Microstructures created at the fusion zones of TIG-welded joints consist of coarse acicular $\alpha^{\prime}$ while that of the joint formed by LB welding demonstrate far finer acicular $\alpha^{\prime}$ structures due to the much faster cooling rate of the laser welding process [14].

Powder interlayer bonding (PIB) was originally conceived as a repair method for the joining of aerospace alloys. The method has already proved successful at delivering high integrity bonds in titanium alloys $[15,16]$ gamma titanium aluminides and nickel alloys[17]. The PIB process is a solidstate joining process that utilises a metallic powder interlayer between the two surfaces being joined. The technique complements other more mature joining techniques and offers the prospect of salvaging otherwise redundant gas turbine components [18]. The process can be regarded as three related phases [15]: the initial, intermediate and final phase. Initially, localised bonding between neighbouring powders and the faying surfaces occurs with the formation of necks. Limited deformation of the powder particles follows and bonding proceeds by vacancy migration away from the neck regions. This results in a flow of material in the opposite direction with continued growth of necks and pore shrinkage between the powders. Most of the powder deformation occurs during intermediate phase of the process, before final densification of the bond and elimination of isolated pores occurs during the final phase [16]. By introducing a powder interlayer into the bond, the dependency of the bonding process on smooth surface finish is reduced by eliminating asperities on the faying surfaces. The PIB process has advantages over fusion welding techniques where localised heating results in very narrow FZs. Heat is supplied via induction heating, while inert gas shielding protects the $\mathrm{FZ}$ of the bond from oxidation at the bonding temperatures.

\section{Experimental}

All Ti-6-4 and Ti-6-2-4-6 material used for this work was supplied by Rolls-Royce Plc. The Ti-6-4 material in the form of a forged billet is in conjunction with $\beta$-forged Ti-6-2-4-6 material. Bonding specimens $10 \mathrm{~mm}$ in diameter were removed from both forgings as illustrated in Fig. 1a and $b$. Both the Ti-6-4 and Ti-6-2-4-6 gas atomised powders used
Fig. 1 Fatigue test specimens a LCF and $\mathbf{b} \mathrm{HCF}$, and orientation removed c Ti-6-4 and d Ti-6-2-4-6
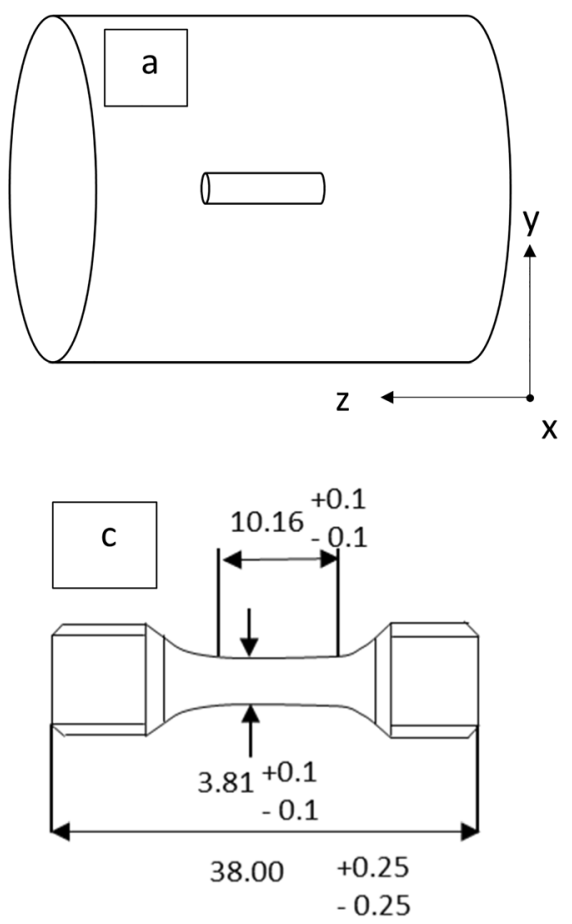

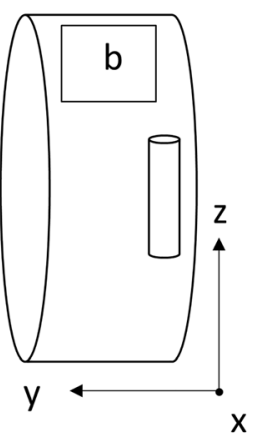

$+0.1$

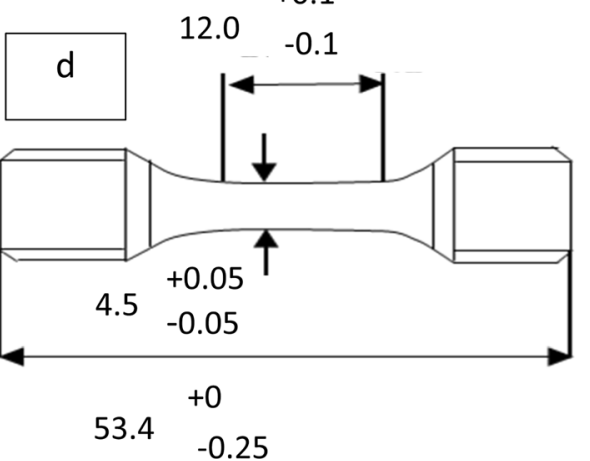


in this study were supplied by LPW Technology Ltd. The Ti6-4 powder had a particle size between $15-45 \mu \mathrm{m}$, while the Ti-6-2-4-6 had a particle size between 25 and $53 \mu \mathrm{m}$.

The forged Ti-6-4 billet material (Fig. 2a, b) displayed an equiaxed microstructure, with an average primary alpha $\left(\alpha_{p}\right)$ grain size of $\sim 20 \mu \mathrm{m}$ and $\sim 7 \% \beta$ retained between the $\alpha_{p}$ grains. The Ti-6-2-4-6 $\beta$-forged material (Fig. 2c, d) exhibits a microstructure composed of prior $\beta$ grains with an average grain size of $\sim 300 \mu \mathrm{m}$, with fine $\alpha$ lamellar, average width1 $\mu \mathrm{m}$, retained in a $\beta$ matrix. Fine secondary $\alpha\left(\alpha_{\mathrm{s}}\right)$ platelet colonies $50-200 \mathrm{~nm}$ in width were found in the $\beta$ matrix.

Both the Ti-6-4 and Ti-6-2-4-6 alloys contained modest transverse texture components of $\sim 5$ times random in their testing direction, as illustrated in Fig. $3 a$ and $b$.

Interlayer pastes were created by combining the relevant powder with deionised water, cellulose powder and glycerol before being applied to one of the faying surfaces. Paste thickness was controlled and retained in position utilising a measuring jig. Prior to the joining process, both parts being joined were ultrasonically cleaned in industrial acetone for $30 \mathrm{~min}$. Bonds were performed in an argon shielded environment as illustrated in Fig. 4, protecting the FZ from the local environment. Care was taken to minimise contamination during the interlayer preparation and handling. All equipment used to facilitate interlayer preparation was cleaned with acetone prior to mixing, along with test machine surfaces and fixings in the proximity of bonding process.

Specimens were initially heated by a water-cooled induction coil to an intermediate temperature of $900^{\circ} \mathrm{C}$, at a heating rate of $6{ }^{\circ} \mathrm{C} / \mathrm{s}$, before being brought to the relevant bonding temperatures in the specific alloy's $\alpha+\beta$ region at a heating rate of $0.5{ }^{\circ} \mathrm{C} / \mathrm{s}$. Bonded specimens were air-cooled to room temperature on completion of bonding. Type $\mathrm{N}$ thermocouples welded in place within $1 \mathrm{~mm}$ of the faying surface were used to measure the temperature of the FZ; these were connected to a calibrated Fluke 54 II thermometer.

Completed bonds were sectioned then mounted in conductive Bakelite to facilitate the microstructural analysis of the bond region. A standard grinding and polishing process was used to prepare all sectioned. All sectioned samples were then etched with Kroll's reagent. Microstructural and microtextural analysis was performed on a Hitachi SU3500 scanning electron microscope (SEM) equipped with electron backscatter diffraction (EBSD) and energy dispersive spectroscopy (EDS). Average grain sizes were calculated using the mean linear intercept (M.L.I.) method. Retained beta volumes were identified in several images and determined manually. The LCF tests were performed at room temperature with a trapezoidal waveform at $0.25 \mathrm{~Hz}$ at an $\mathrm{R}$ ratio of 0.01 . Tests were performed on a servo hydraulic test machine with a maximum load capacity of $50 \mathrm{kN}$, with a run out of 100,000 cycles. HCF tests were performed at room temperature with a sinusoidal waveform at $90 \mathrm{~Hz}$ at an $\mathrm{R}$ ratio of 0 . Tests were performed on a vibrophore test machine with a load capacity of $100 \mathrm{kN}$, with a run out of 10,000,000 cycles. All LCF and HCF tests were carried out in accordance with BS EN 6072:2010 aerospace series, metallic materials, test methods, constant amplitude

Fig. 2 Microstructure of $\mathbf{a}, \mathbf{b}$ Ti6-4 billet and c, d Ti-6-2-4-6 $\beta$ forged material
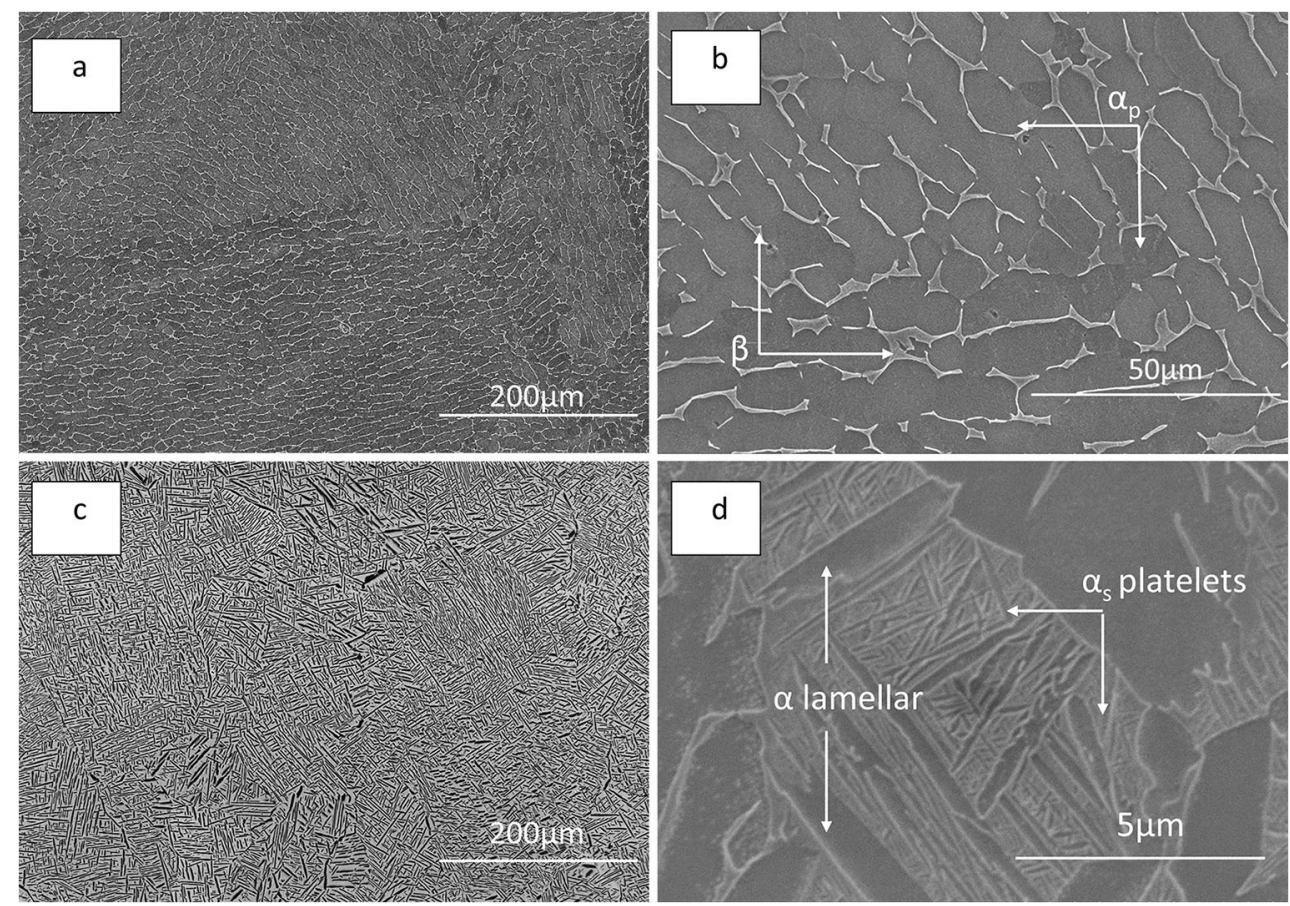
Fig. 3 EBSD-derived pole figures, IPF//Z for a Ti-6-4 alloy and b Ti-6-2-4-6 alloy
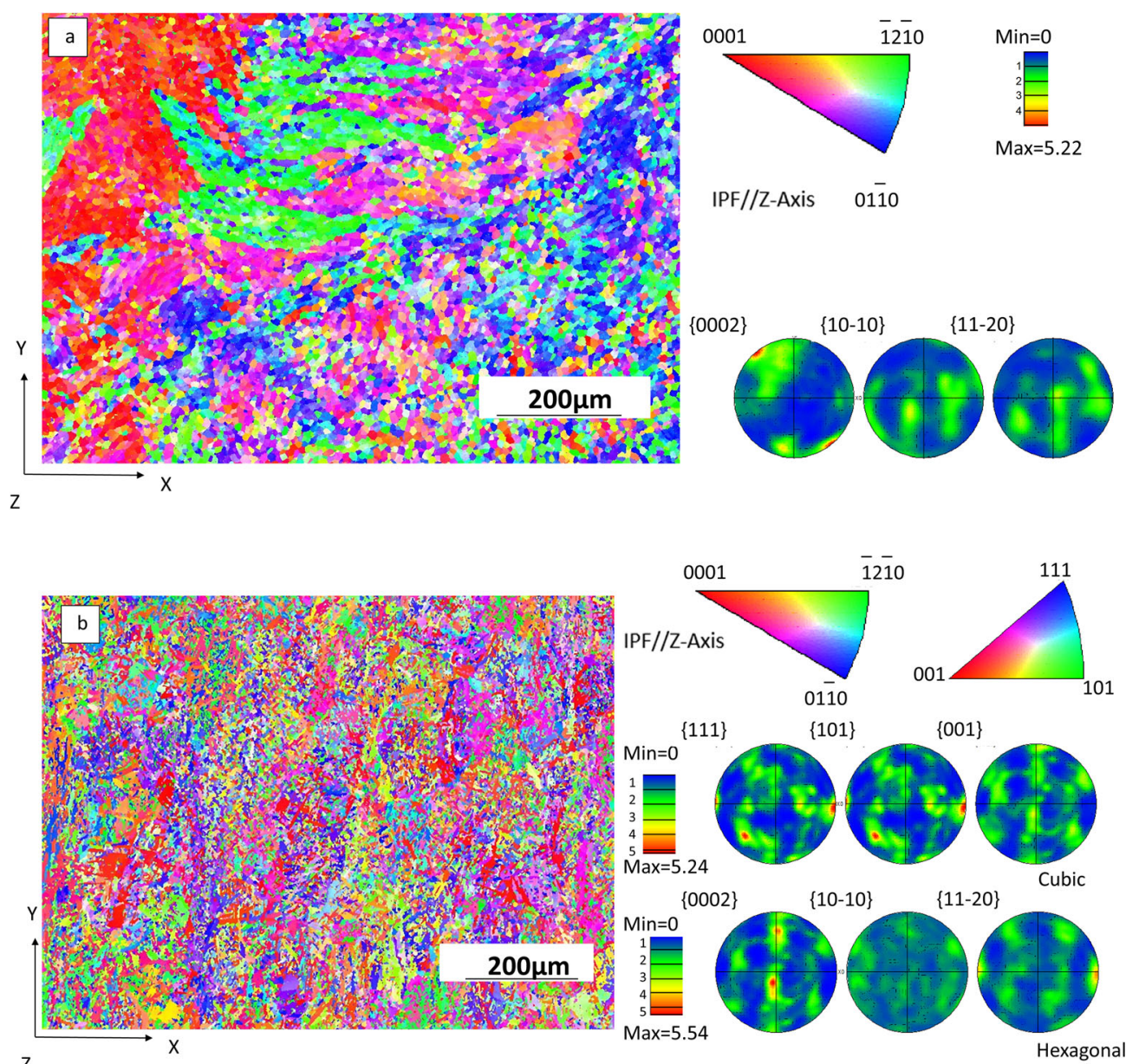

fatigue testing [19]. LCF and HCF specimens used in this study were machined from the bonded test pieces for subsequent mechanical testing; they were finished to a surface roughness of $1.6 \mu \mathrm{m}$ and are illustrated in Fig. 1c and d.

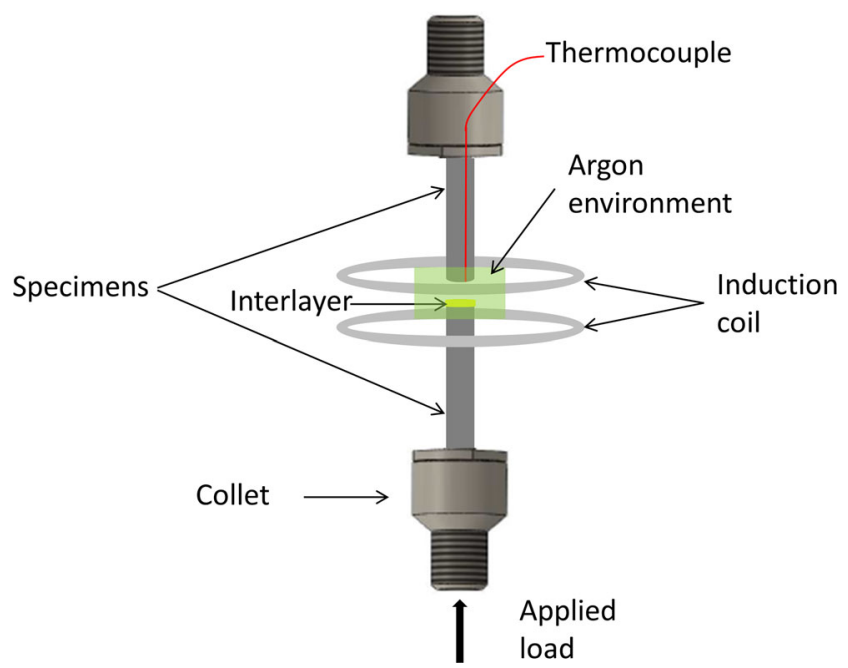

Fig. 4 Schematic of the powder interlayer bonding apparatus

\section{Results}

\subsection{Ti-6-4 LCF results}

Normalised LCF results for the Ti-6-4 billet material are illustrated in Fig. 5. The results indicate that the LCF performance of the bonds created by the PIB process utilising 1-45 $\mu \mathrm{m}$ powder sizes was equal to or better than the performance of the base material throughout the whole of the fatigue curve.

\subsection{Ti-6-2-4-6 HCF results}

Normalised HCF results for the $\beta$-forged Ti-6-2-4-6 material are illustrated in Fig. 6. The results indicate that the HCF performance of the Ti-6-2-4-6 bonds created by the PIB process falls below that of the as received material.

\section{Discussion}

When evaluating the LCF test results for the Ti-6-4 material shown in Fig. 5, we see that bonds created via the PIB process 
Fig. 5 LCF results for Ti-6-4 billet and PIB specimens

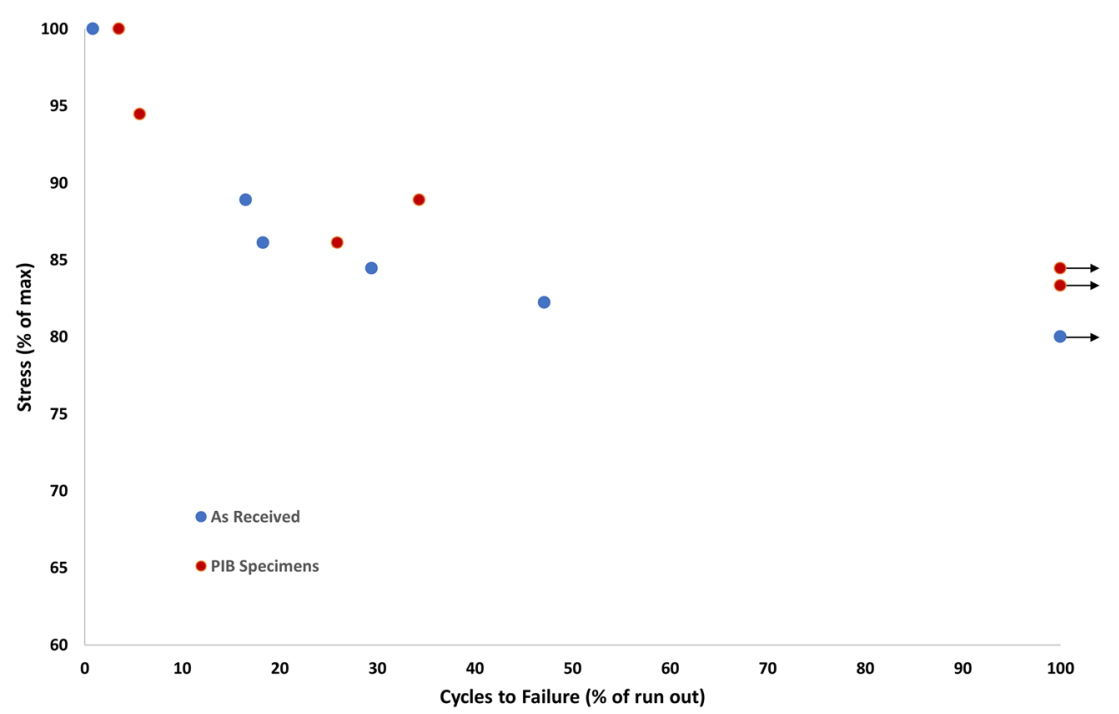

offer stronger LCF performance when compared to the base Ti-6-4 material. The microstructures of the PIB specimens is likely to be a major contributing factor in the improvement in fatigue performance seen over the base Ti-6-4 material. As seen in Fig. 7, the microstructure of the bondline and a section of the HAZ that extends beyond that of the LCF specimen (Fig. 1c) gauge length has recrystalised into a bi-modal structure during the bonding process. At the bondline, the microstructure contains $\sim 35 \% \alpha_{p}$ grains with an average grain size of $\sim 7 \mu \mathrm{m}$. This increased to $\sim 41 \% \alpha_{p}$ grains, average grain size $\sim 15 \mu \mathrm{m}$ and $48 \% \alpha_{p}$ grains with an average grain size of $\sim 19 \mu \mathrm{m}$ respectively, at locations $2.5 \mathrm{~mm}$ and $5 \mathrm{~mm}$ away due to the reduction in temperature at these locations during the bonding cycle.

This bi-modal structure improves the LCF performance by reducing the slip length which plays a major role in LCF performance. The $\alpha$ grain size determines the slip length in equiaxed microstructures, which significantly effects their mechanical properties. It is important to note that the effective slip length may be far greater than the size of the $\alpha$ grains as strong crystallographic textures may exist in equiaxed microstructures as illustrated in Fig. 3a, where macro zones or effective structural units (ESU) approaching $300 \mu \mathrm{m}$ in length are visible for the Ti-6-4 alloy.

For bi-modal structures, the transformed $\beta$ grain size has the most significant effect on mechanical properties [8]. The $\beta$ grain size is typically equal to the distance between $\alpha_{p}$ grains in recrystalised microstructures and is related to the volume fraction of $\alpha_{p}$ grains, which in turn is largely determined by the bonding/recrystallisation temperature. This small $\beta$ grain size therefore limits the slip length in these microstructures and improves resistance to fatigue crack nucleation. Crack

Fig. 6 HCF results for Ti-6-2-4-6 $\beta$-forged billet and PIB specimens

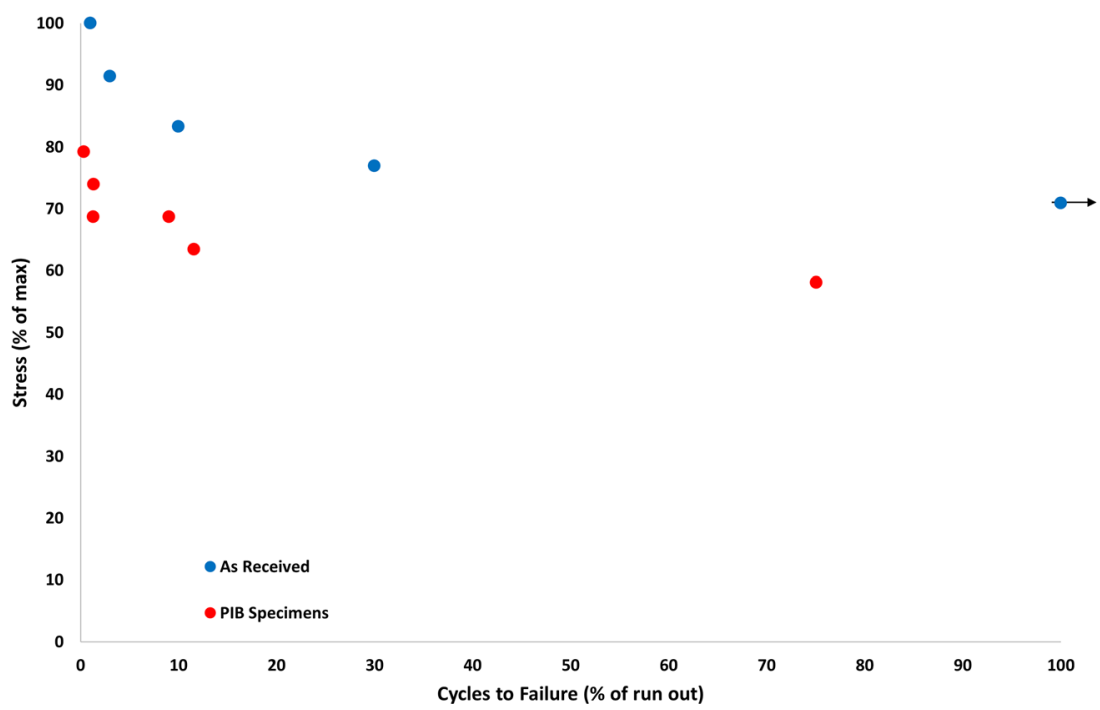




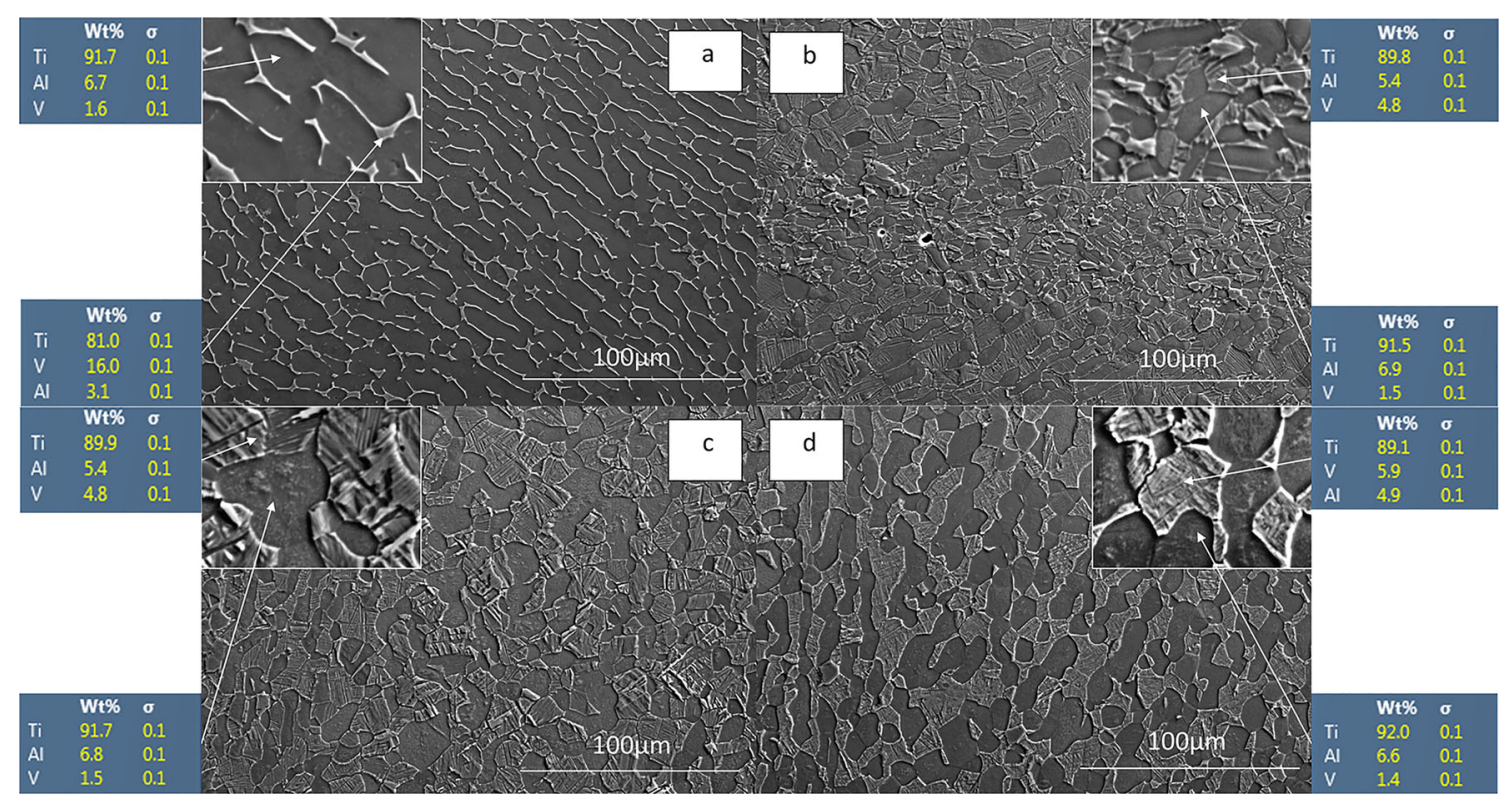

Fig. 7 EDX analysis of Ti-6-4 a billet material, $\mathbf{b}$ at bondline, $\mathbf{c}$ at $2.5 \mathrm{~mm}$ from bondline, $\mathbf{d} 5 \mathrm{~mm}$ from bondline

nucleation and microcrack propagation has been shown to occur in the interconnected $\alpha$ grains in equiaxed structures, while they nucleate in [8] and tend to propagate through the lamellar grains of bi-modal microstructures. The lamellar grains are softer than $\alpha_{p}$ grains due to an alloy element partitioning effect where strong $\alpha$ or $\beta$ stabilisers partition into their respected phases during formation of $\alpha_{p}$ and $\beta$ grains. This can be seen in Fig. 7b-d where both aluminium and vanadium partition into the $\alpha$ and $\beta$ phases respectively at the bondline and locations $2.5 \mathrm{~mm}$ and $5 \mathrm{~mm}$ away. Microcracks have also been shown to propagate slower through the bi-modal structure when compared to equiaxed microstructures. The improvement in fatigue performance due to the microstructure transformation overcomes any reduction in performance that can be attributed to any retained porosity after the bonding cycle. Previous work [15] has shown that retained porosity in the bond contributes to a reduction in strength of $\sim 10 \%$ for forged Ti-6-4 material joined via the PIB process. It would be reasonable to expect a reduction in LCF performance of a similar amount as this is strongly linked to the strength of the material [20] when other conditions such as surface finish are constant.

While the HCF results for the Ti-6-2-4-6 material were also very promising, they fell below what would be expected from unbonded $\beta$-forged Ti-6-2-4-6 material. However, the fatigue performance correlates extremely well with previous HCF results

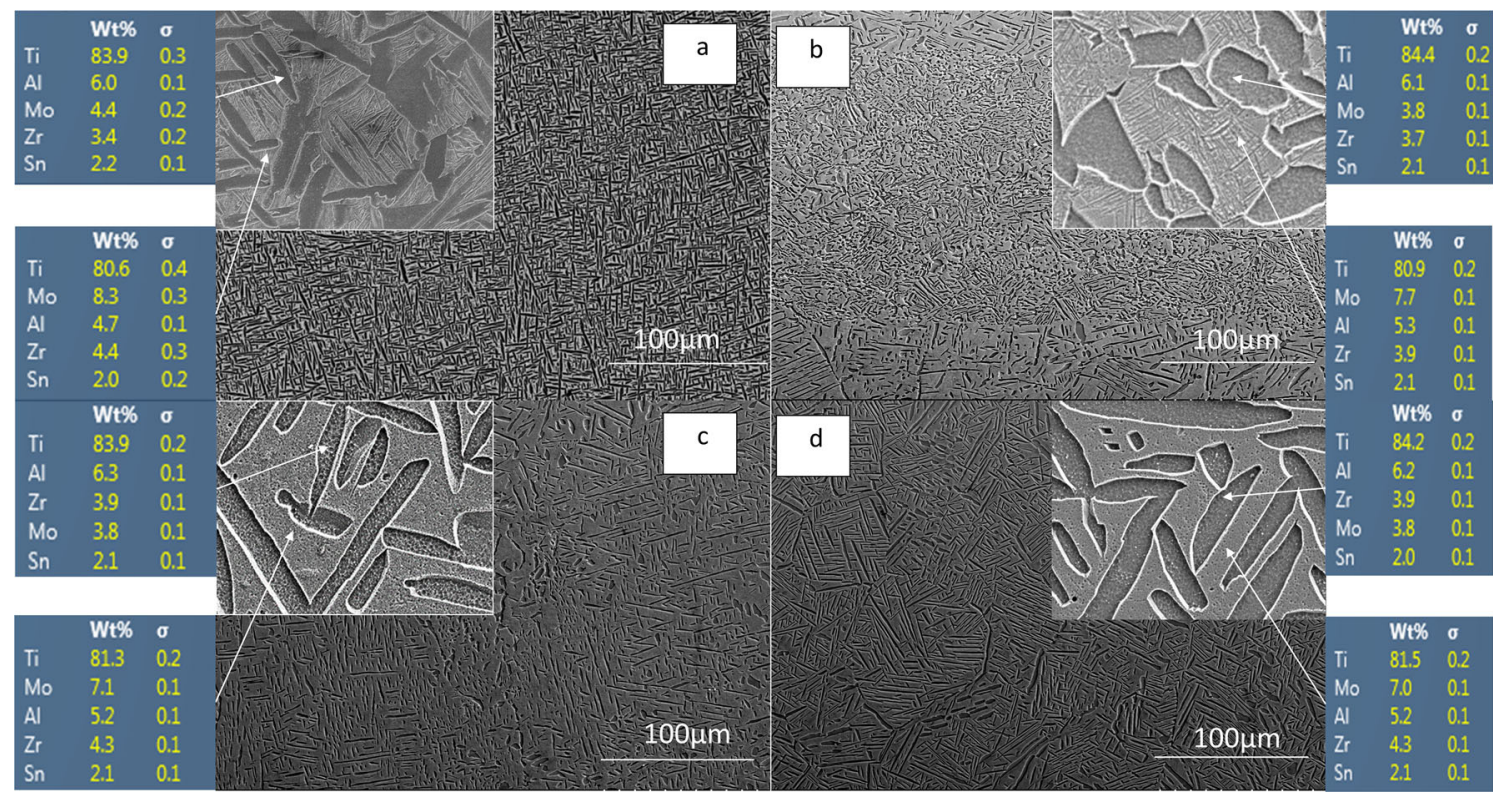

Fig. 8 EDX analysis of Ti-6-2-4-6 a base material, $\mathbf{b}$ at bondline, $\mathbf{c}$ at $2.5 \mathrm{~mm}$ from bondline, $\mathbf{d} 5 \mathrm{~mm}$ from bondline 
Fig. 9 EBSD-derived IPF//X through bond region and pole figures for a Ti-6-4 alloy and $\mathbf{b}$ 62-4-6 alloy a
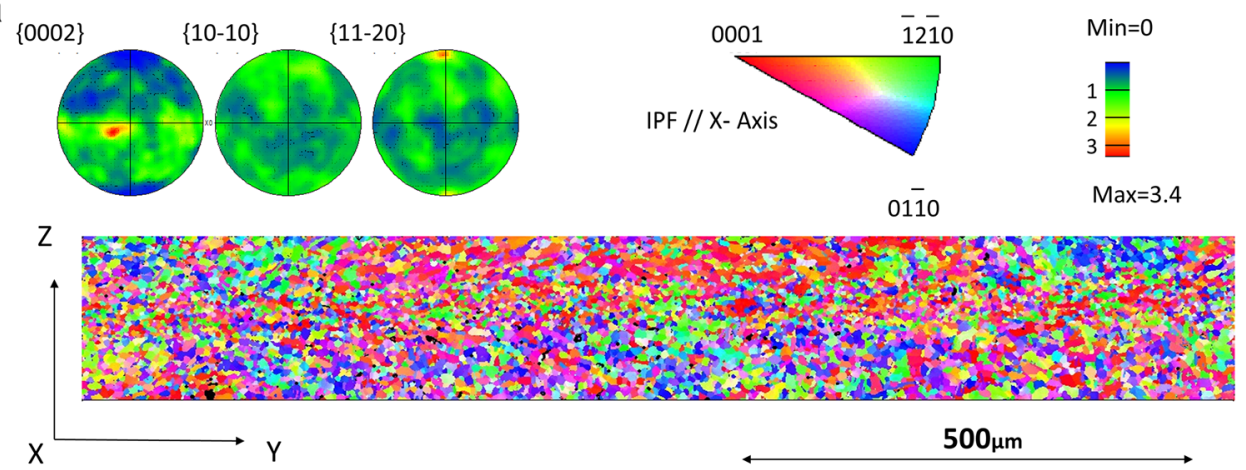

b

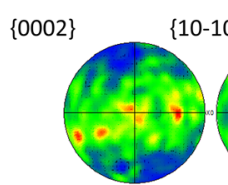

$\{0002\}$

$\{10-10\}$

$\{11-20\}$

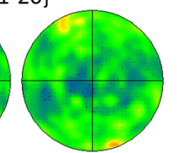

$\{11-20\}$
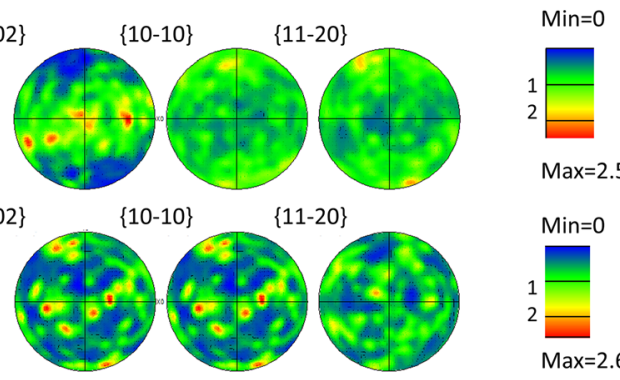

$\operatorname{Max}=2.51$

IPF // X-Axis

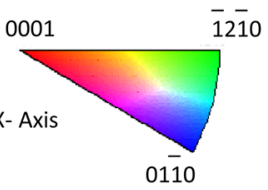

$M i n=0$
$M a x=2.62$
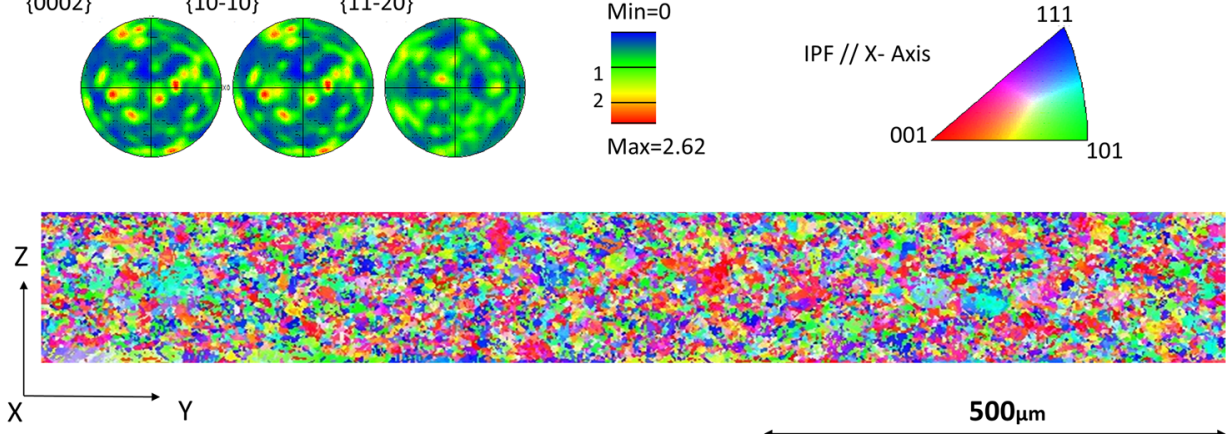

for welded material. Unlike the Ti-6-4 material, the $\beta$-forged Ti6-2-4-6 alloy does not benefit from the transformation of its microstructure through the bond region and HAZ. The microstructure of the bondline changes from a basketweavelike structure with interlocking $\alpha$ lamellar, becoming much more disorganised and bi-modal in nature, with a mixture of coarse
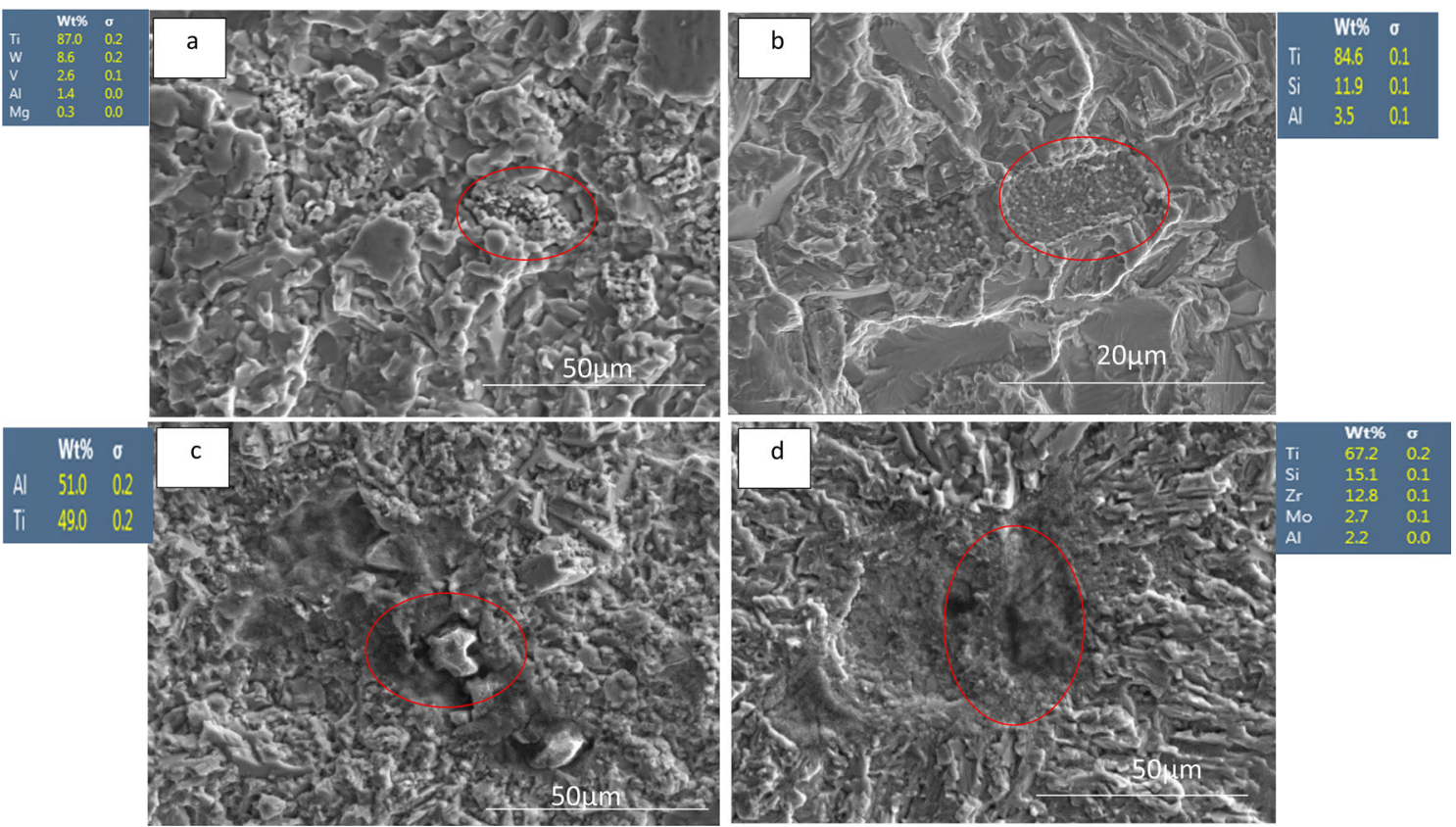

Fig. 10 EDX analysis of contamination found at initiation sites in Ti-6-4 (a, b) and Ti-6-2-4-6 (c, d) 
individual laths and globular $\alpha_{p}$ with an average grain size of $\sim 6$ $\mu \mathrm{m}$, in a transformed $\beta$ matrix. The alloy element partitioning effect illustrated in Fig. 8, for the Ti-6-2-4-6 alloy, reduces the strength of the lamellar grains in the bi-modal structure below that of the fully lamellar microstructure, resulting in a weaker HCF response at room temperature[8]. At approximately $2.5 \mathrm{~mm}$ away from the bondline, the microstructure has coarsened significantly, regaining some of the basketweave features with long interlocking $\alpha$ lamellar, although there are still globular $\alpha_{p}$ present. It is also apparent that there is a lack of $\alpha_{s}$ present in the $\beta$ grains, effectively weakening the material by increasing the effective slip length through these regions $[8,15,21]$. This lack of $\alpha_{s}$ is still apparent approximately $5 \mathrm{~mm}$ away from the bondline, although the microstructure becomes increasingly more basketweave in nature, albeit coarser than the starting structure.

Texture does not appear to play a major role in the fatigue performance of either Ti-6-4 or Ti-6-2-4-6 PIB specimens, as illustrated in Fig. 9 a and b; there are weak texture intensities through the bond regions of both alloys with little evidence of macro zones being present.

While all the base material specimens failed from initiation sites emanating from the surface, there are instances of the Ti6-4 and Ti-6-2-4-6 PIB specimens failing from initiation sites originating sub surface in the bond region. Although the fatigue performance of both alloys was very positive, some of these sub surface initiations, due to contamination of the powder interlayers, appear to have reduced fatigue life to some degree. This contamination likely enabled early crack nucleation around these noncoherent particles leading to compromised fatigue performance. Contamination found at the sub surface initiation sites included trace amounts of silicon, tungsten and aluminium as illustrated in Fig. 10a-d.

It has not been possible to identify the exact source of the contamination to date, but it is thought that it occurred either during interlayer preparation, handling during bonding or possibly via the original powder supply. No trace of contamination, however, was found in several samples of powder that were analysed.

\section{Conclusions}

This study investigated the fatigue performance of two titanium alloys commonly employed in the aerospace industry, namely Ti-6-4 and Ti-6-2-4-6, joined via the PIB process. Conclusions are presented below:

- The LCF performance of forged Ti-6-4 joined via the powder interlayer bonding (PIB) process outperformed that of the base forged material. The PIB process transforms the microstructure to such an extent that any loss in fatigue response due to any retained porosity is offset by the resultant microstructure.

- The HCF performance of $\beta$-forged Ti-6-2-4-6 joined via the PIB falls below the base forged material. However, the HCF performance is deemed satisfactory for repaired components.

- Contamination of interlayers proved to be problematic during the study with several tests being compromised.

Open Access This article is licensed under a Creative Commons Attribution 4.0 International License, which permits use, sharing, adaptation, distribution and reproduction in any medium or format, as long as you give appropriate credit to the original author(s) and the source, provide a link to the Creative Commons licence, and indicate if changes were made. The images or other third party material in this article are included in the article's Creative Commons licence, unless indicated otherwise in a credit line to the material. If material is not included in the article's Creative Commons licence and your intended use is not permitted by statutory regulation or exceeds the permitted use, you will need to obtain permission directly from the copyright holder. To view a copy of this licence, visit http://creativecommons.org/licenses/by/4.0/.

\section{References}

1. Peters M, Kumpfert J, Ward CH, Leyens C (2003) Titanium alloys for aerospace applications. Adv Eng Mater 5(6):419-427

2. Inagaki I, Tsutomu T, Yoshihisa S, and Nozomu A (2014) Application and features of titanium for the aerospace industry.

3. Whittaker M (2011) Titanium in the gas turbine engine, Adv Gas Turbine Technol, vol. 4.

4. Esslinger $\mathbf{J}$ (2003) Titanium in aero engines demands on titanium alloys and processes in aero engines, Proc. 10thWorld Conf. Titan., pp. $2845-2852$

5. Pederson R (2002) Microstructure and phase transformation of Ti6Al-4V. Luleå University of Technology

6. Properties and processing of TIMETAL 6-4, 1998.

7. TIMET, TIMETAL 6-2-4-6 datasheet, 2000.

8. Lütjering $G$ (1998) Influence of processing on microstructure and mechanical properties of $(\alpha+\beta)$ titanium alloys. Mater Sci Eng A 243(1-2):32-45

9. Imam M, Gilmore C (1983) Fatigue and microstructural properties of quenched Ti-6Al-4V. Metall Trans A 14(1):233-240

10. Donachie MJ (2000) Titanium: a technical guide, 2nd Editio. Materials Park, Ohio

11. Wagner L and Bigoney J (2003) Fatigue of titanium alloys, in Titanium and titanium alloys fundamentals and applications, pp. 153-186.

12. Lütjering G, Williams JC (2007) Titanium, 2nd ed. Springer

13. Yung KC, Ralph B, Lee WB, Fenn R (1997) An investigation into welding parameters affecting the tensile properties oftitanium welds. J Mater Process Technol 63(96):759-764

14. Yunlian Q, Ju D, Quan H, Liying Z (2000) Electron beam welding, laser beam welding and gas tungsten arc welding of titanium sheet. Mater Sci Eng A 280(1):177-181

15. Davies P, Davies H, Marchisio S (2019) The bonding of additive manufactured Ti-6Al-4V via the powder interlayer bonding (PIB) process. In: The 14th World Conference on Titanium 
16. Davies P, Johal A, Davies H, Marchisio S (2019) Powder interlayer bonding of titanium alloys: Ti-6Al-2Sn-4Zr-6Mo and Ti-6Al-4V. J Adv Manuf Technol

17. Stanners O, John S, Davies H, Watkins I, and Marchisio S (2019) The effect of processing variables on powder interlayer bonding in nickel-based superalloys, Materials (Basel)., pp. 1-13

18. Forsdike J (2009) Novel joining and repair of aerospace. Swansea University

19. ASD-STAN, Aerospace series-Metallic materials-Test methodsConstant amplitude fatigue testing.pdf. 2010

20. Davies PD (2014) Fatigue characterisation of Novell titanium alloys for future aero engine components, Swansea University

21. Thomas M, Hewitt J, Bache M, Thomas R, Garratt P, and Kosaka Y, (2016) Determination and analysis of the cyclic and dwell fatigue performance of Timetal @ 575, in Proceedings of the 13th World Conference on Titanium, pp. 979-984.

\section{Future work}

It is believed that the PIB technique is suitable for joining a variety of aerospace alloys. Although these initial fatigue results are very promising, further work needs to be carried out to avoid the contamination of interlayers witnessed during this study. Initial trials have begun to investigate the effect of powder particle size on the microstructure of the bond region. The authors believe this is a way of further refining the bond region and improving the mechanical properties of alloys joined via the powder interlayer bonding method.

Publisher's note Springer Nature remains neutral with regard to jurisdictional claims in published maps and institutional affiliations. 